\title{
Edyta Rudolf
}

ORCID: 0000-0001-7282-965X

Uniwersytet Medyczny im. Piastów Śląskich we Wrocławiu

\section{W mocy fantasy — dyskurs wokół gatunku rodzimych czytelników, twórców, wydawców, krytyków i badaczy}

https://doi.org/10.19195/0867-7441.25.32

Recenzja: Katarzyna Kaczor, Z „getta” do mainstreamu. Polskie pole literackie fantasy (1982-2012), Towarzystwo Autorów i Wydawców Prac Naukowych „Universitas", Kraków 2017, ss. 388.

Slowa kluczowe: fantasy, literatura polska, Katarzyna Kaczor

Keywords: fantasy, Polish literature, Katarzyna Kaczor

Teoria literatury fantasy to wciąż relatywnie nowy obszar badawczy, szczególnie jeśli porównana zostanie bibliografia polskich opracowań naukowych $\mathrm{z}$ analogicznymi pracami w kręgu anglosaskim.

Pierwsze publikacje, które zaczęły pojawiać się na polskim rynku wydawniczym w latach sześćdziesiątych XX wieku, funkcjonowały w swoistej próżni, ponieważ ze względu na politykę państwa literatura popularna była niemal nieobecna, a co za tym idzie odbiorca zazwyczaj nie miał świadomości istnienia rzeszy twórców. Polscy badacze, tacy jak Celestyn Skołuda ${ }^{1}$, Witold Ostrowski ${ }^{2}$, Ryszard Handke $^{3}$, Andrzej Zgorzelski ${ }^{4}$, jako pierwsi zaczęli dostrzegać potencjał fantastyki, ale fantasy, jako odróżniający się nurt w literaturze, długo nie było przedmiotem refleksji naukowej. Pierwsze prace badawcze dotyczące fantasy powstały dość późno w stosunku do badań zachodnich, bo pod koniec lat osiemdziesiątych XX wieku, natomiast rozwój badań oraz stopniowe wypracowywanie narzędzi do analizy i opisu tego gatunku literatury popularnej można datować dopiero na lata dziewięćdziesiąte XX wieku, kiedy to pojawiła się znacząca liczba tłumaczeń i zaczął się zwiększać zasób rodzimych realizacji literackich. Kolejni badacze literatury fanta-

1 C. Skołuda, O fantastyce w literaturze, „Ruch Literacki” 1960, nr 3, s. 189-196.

${ }^{2}$ W. Ostrowski, The fantastic and the realistic in literature, „Zagadnienia Rodzajów Literackich” 1966, z. 1, s. 54-71.

3 R. Handke, Polska proza fantastyczno-naukowa. Problemy poetyki, Wrocław 1969.

${ }^{4}$ A. Zgorzelski, Fantastyka, utopia, science fiction. Ze studiów nad rozwojem gatunków, Warszawa 1980. 
stycznej, jak Anna Gemra ${ }^{5}$, Bogdan Trocha ${ }^{6}$, Grzegorz Trębicki ${ }^{7}$, Marek Oziewicz ${ }^{8}$ i inni, uczynili fantasy jednym z głównych tematów swoich opracowań.

Mimo rosnącego zainteresowania literaturą i kulturą popularną oraz pojawiania się coraz nowszych prac badawczych dotyczących fantasy ciągle znajdujemy się na początku studiów ${ }^{9}$. Niezwykła popularność tego gatunku literatury popularnej rokrocznie generuje znaczną liczbę premier, a kolejne pokolenia pisarzy i wydawców kreują współczesną przestrzeń literatury fantastycznej, poszerzając znacząco zagadnienia występujące $\mathrm{w}$ niej do tej pory ${ }^{10}$.

Fenomen popularności polskiej literatury fantasy prowokuje do rozważań znacznie ogólniejszej natury i z pewnością warto dokonać pewnych podsumowań, co do tej pory - w formie systemowego opracowania, obejmującego szeroki kontekst procesów dotyczących fantasy i ich analizę w określonym czasie — nie miało miejsca ${ }^{11}$. Tego trudnego zadania podjęła się Katarzyna Kaczor w monografii $Z$, getta" do mainstreamu. Polskie pole literackie fantasy (19822012). Jak pisze autorka, celem tej publikacji nie jest przedstawienie analizy i interpretacji tekstów polskiej fantasy, lecz procesów związanych z kształtowaniem się polskiego rynku wydawniczego, czyli jego twórcy, krytycy, wydawcy, odbiorcy, jak też samego gatunku, zachodzących w latach 1982-2012, oraz analiza sprzężeń zachodzących między poszczególnym składnikami tych procesów ${ }^{12}$. Ramy czasowe, które wyznaczyła sobie badaczka, obejmują rok wydania pierwszego polskiego utworu fantasy — opowiadania Twierdza Trzech Studni Jarosława Grzędowicza - oraz datę umieszczenia Wiedźmina Andrzeja Sapkowskiego w spisie lektur szkolnych ${ }^{13}$. Przedmiotem refleksji stała się zatem zachodząca W ciągu trzech dekad ewolucja polskiej fantasy od zjawiska przypisanego litera-

5 A. Gemra, Fantasy - powrót romansu rycerskiego?, „Literatura i Kultura Popularna” 1998, nr 7, s. 55-73; A. Gemra, E. Rudolf, Fantasy, [hasło w:] Słownik literatury popularnej, red. T. Żabski, Wrocław 2006, s. 149-153.

6 B. Trocha, Degradacja mitu w literaturze fantasy, Zielona Góra 2009.

7 G. Trębicki, Fantasy. Ewolucja gatunku, Kraków 2007.

8 M. Oziewicz, Magiczny urok Narnii. Poetyka i filozofia „Opowieści z Narnii” C.S. Lewisa, Kraków 2005.

9 B. Trocha, Literatura popularna w perspektywie badawczej. Rozważania metodologiczne, [w:] J.Z. Lichański, W. Kajtoch, B. Trocha, Literatura i kultura popularna. Metody: propozycje i dyskusje, Wrocław 2015, s. 79.

10 O kwestiach historycznych w fantastyce pisała A. Gajewska, Zagłada i gwiazdy. Przeszłość w prozie Stanistawa Lema, Poznań 2016; problem transhumanizmu w fantastyce poruszali M. Borowski i M. Sugiera, $W$ pułapce przeciwieństw: ideologie tożsamości, Warszawa 2012; natomiast omówienie motywów religijnych znalazło miejsce w zbiorze Motywy religijne we współczesnej fantastyce, red. M.M. Leś, P. Stasiewicz, Białystok 2014.

11 Taką próbę podjęła Małgorzata Tkacz, jednak autorka skupiła się głównie na zestawieniu definicji fantasy. Zob. eadem, Baśnie zbyt prawdziwe. Trzydzieści lat fantasy w Polsce, Gdańsk 2012.

12 K. Kaczor, Z ,,getta” do mainstreamu. Polskie pole literackie fantasy (1982-2012), Kraków 2017.

13 Ibidem, s. 9. 
turze popularnej, a więc marginalnego, po wejście w przestrzeń mainstreamu ${ }^{14}$. Wybrany przedział czasowy jest zasadny, obejmuje bowiem burzliwe przemiany, niemal rewolucję, jaka dokonała się na polskim rynku wydawniczym, żeby tylko wspomnieć likwidację Głównego Urzędu Kontroli Publikacji i Widowisk w 1990 roku $^{15}$.

Kaczor podzieliła książkę na dwie części — pierwsza prezentuje polskie pole literackie fantasy, jego genezę i ewolucję. W celu realizacji swoich założeń autorka posłużyła się koncepcją pola Pierre'a Bourdieu ${ }^{16}$, które można zdefiniować jako

„strukturę relacji” pomiędzy osobami działającymi, praktykami i przedmiotami właściwymi dla danej dziedziny aktywności. Tak więc w przypadku literatury przynależą tu: pisarze, wydawcy, krytycy i czytelnicy, twórczość, działalność wydawnicza, lektura oraz dzieła ${ }^{17}$.

Według autora Regut sztuki twórca zostaje wykreowany przez pole literackie, albowiem choć wykonuje najbardziej widoczny komponent dzieła sztuki, to uwikłany jest w skomplikowany układ relacji i wpływów uczestników pola. Pole staje się miejscem ,antagonistycznej koegzystencji dwóch sposobów produkcji oraz obiegu dóbr”, a strategie ,producentów” literatury rozkładają się od całkowitego podporządkowania się oczekiwaniom rynku po absolutną wolność wobec niego $^{18}$. Niebagatelną rolę odgrywa tu pytanie o rolę lidera, czyli status artysty uznanego, który swoją pozycję zawdzięcza głównie sprzyjającym warunkom istniejącym w polu literackim. Poszczególni uczestnicy starają się zdobyć dominację, uzyskując odpowiednią pozycję opiniotwórczą oraz odnosząc sukces rynkowy ${ }^{19}$.

Kaczor nie potraktowała teorii francuskiego socjologa ortodoksyjne, lecz przełożyła dyskurs Bourdieu na pojęcia używane w literaturoznawstwie i skupiła się na tym, co może badaczowi literatury i kultury popularnej w omawianej koncepcji wydawać się użyteczne i interesujące. Na wstępie autorka wyodrębniła trzy okresy: lata 1982-1990, lata 1991-2000 oraz etap przypadający na pierwszą dekadę XXI wieku. W pierwszym okresie formowało się pole fantasy i uzyskało autonomię od pola science fiction, w drugim wzrosła liczba teks-

14 Mainstream rozumiany tu jest jako „szeroko dostępna kultura głównego nurtu”. Zob. ibidem, s. 7-8.

15 Ibidem, s. 59-60. Szerzej na ten temat P. Czapliński, Powrót centrali, „Kresy” 1995, nr $1-2$, s. 31-45.

16 P. Bourdieu, Teoria obiektów kulturowych, przeł. A. Zawadzki, [w:] Odkrywanie modernizmu. Przekłady i komentarze, red. R. Nycz, Kraków 1998, s. 259-280.

17 Zob. R. Ponton, Champ littéraire, [hasło w:] P. Aron, O. Saint-Jacques, A. Viala, Le Dictionnaire de la littérature, Paris 2002, s. 84, cyt. za: K. Gajewski, „Reguly sztuki: geneza i struktura pola literackiego", Pierre Bourdieu, przet. Andrzej Zawadzki, red. nauk. Małgorzata Sugiera, Kraków 2001 [recenzja], „Pamiętnik Literacki” 97, 2006, nr 2, s. 257.

18 P. Bourdieu, Reguly sztuki. Geneza i struktura pola literackiego, przeł. A. Zawadzki, Kraków 2001, s. 219.

19 Ibidem, s. 219-227. 
tów tłumaczonych i rodzimych autorów, czemu towarzyszyły walki o zyskanie dominacji między Andrzejem Sapkowskim i pozostałymi uczestnikami pola. Ostatni etap zaś obejmuje okres, kiedy fantasy przestaje być zjawiskiem niszowym i staje się elementem mainstreamu oraz przedmiotem dyskursu literaturoznawczego.

W każdym z tych trzech etapów autorka uwzględniła wpływy wszystkich uczestników znajdujących się w polu fantasy na jego rozwój i kształt. Jednocześnie oprócz uczestników pola - pisarzy, wydawców, redaktorów czasopism i recenzentów - uwzględniła wpływ czytelników, systemu nagród literackich oraz ruchu fanowskiego. Ujęcie takie pozwoliło na pełniejsze zrozumienie zachodzących w owym czasie procesów — od kształtowania się liderów po konflikty i walkę o dominację w polu. Kaczor wykazała też w sposób kompletny, że w wypadku fantasy zacierają się granice między krytyką a pisarstwem, część autorów wykraczała bowiem poza swoje pole, publikując teksty promujące, edukujące i kształtujące recepcję. Zatem, nie mając odpowiednich kompetencji i narzędzi, formułowała kryteria wartościujące ${ }^{20}$.

Niepokojąca wydaje się konkluzja wyłaniająca się z zakończenia pierwszej części $Z$, getta" do mainstreamu, iż to właśnie Andrzej Sapkowski narzucił sposób definiowania, wartościowania i reguł dyskursu nie tylko czytelnikom i wydawcom, lecz także literaturoznawcom. Pisarz uznany za lidera przejął kompetencje i miejsce należące do krytyków i badaczy literatury. Autorka precyzyjnie odtwarza mechanizm „przejęcia” kompetencji, co wydaje się niezwykle cenne w celu uniknięcia podobnych zjawisk ${ }^{21}$.

Pozostaje też wątpliwość co do wyboru przez badaczkę metodologii, konkretnie koncepcji pola literackiego Pierre'a Bourdieu, stosowanej do analizy i interpretacji literatury wysokiej. Teoria ta wymagała licznych działań adaptacyjnych i powstaje pytanie, czy autorka poradziła sobie oraz czy osiągnęła zamierzony efekt. Według mnie Kaczor osiągnęła zamierzone cele, choć niektórzy czytelnicy mogliby oczekiwać bardziej tradycyjnego podejścia i prezentacji problemu historii ewolucji polskiej fantasy we właściwym dla badań historyczno-literackich ujęciu diachronicznym. Jednocześnie recenzowane opracowanie mieści się w zakresie badań kulturowych, czego manifestacją jest dobór metodologii, kontekstów i analizowanych aspektów interesującego badaczkę zjawiska, jakim jest nobilitacja fantasy jako konwencji literackiej w polskim polu kultury.

Druga część $Z$,getta” do mainstreamu dotyczy polskiego dyskursu fantasy. Badaczka skrupulatnie analizuje uwarunkowania i przebieg dyskusji naukowych wokół terminologii. Działania te pozwoliły na zdefiniowanie pola przedmiotu fantasy oraz ogląd ewolucyjnych zmian zachodzących w polskim dyskursie kry-

20 K. Kaczor, op. cit., s. 191.

21 Ibidem, s. 90-124, 139-140, 192. 
tycznym. Jako początek formowania się polskiego aparatu pojęciowego autorka omawianej książki wskazuje na wydanie przekładu Hobbita Tolkiena w 1960 roku. Wyznacza tym samym punkt wyjścia do analizowanych w dalszej części pracy definicji, czyli ujęcia fantasy w kontekście baśni dla dorosłych ${ }^{22}$. Wykazuje, jak sposób definiowania nie tylko określa fantasy jako przedmiot refleksji, lecz także kształtuje proces recepcji ${ }^{23}$. Ponieważ w Polsce, jak już wspomniano, brakowało refleksji teoretycznej, wszyscy uczestniczący w dyskursie formułowali własną definicję na podstawie poetyki klasycznej, właściwej dla polskiej teorii literatury, bądź podejmowali próby odmiennego definiowania fantasy jako zjawiska literackiego, zgodnego z teoriami funkcjonującymi w dyskursie anglosaskim. Kaczor przedstawia różnorodność kryteriów i konwencji wpływających na badania nad fantasy, w których brali udział nie tylko literaturoznawcy, lecz także thumacze i członkowie fandomu.

Reasumując, można śmiało powiedzieć, że $Z$ „,getta” do mainstreamu jest pierwszym tak wieloaspektowym opracowaniem poświęconym zjawisku, które na przełomie wieków stało się dystynktywne dla rodzimej literatury popularnej, i jest drugą po Geralcie, czarownicach $i$ wampirze. Recyklingu kulturowym Andrzeja Sapkowskiego (2004) próbą rekonstrukcji przez Kaczor różnorodności mechanizmów działających zarówno w środowisku twórców i wydawców, jak i badaczy literatury. Całość książki, mimo obecności niezwykłej liczby nazwisk, dat i tytułów, ma przejrzysty układ. Publikacja zawiera omówienie metody, wykresy i diagramy ilustrujące konkretne zjawiska, w tym prezentacje pola, obejmujące lata 1891-2011 kalendarium oraz sześćdziesięciostronicową bibliografię.

Jednocześnie należy zaznaczyć, że choć pierwsza część tworzy całość kompletną i zamkniętą, o tyle druga otwiera dopiero drogę dalszej dyskusji. Wiele tez autorki może wzbudzić wątpliwości, jak chociażby uznanie artykułu Marka Oziewicza prezentującego założenia Diane Waggoner i jego monografii Magiczny urok Narnii. Poetyka i filozofia „Opowieści z Narnii” C.S. Lewisa za teksty inicjujące nowy nurt dyskursu w polskich badaniach fantasy. Pojawia się bowiem pytanie, czy rzeczywiście publikacje te wpłynęły na kolejne prace polskich badaczy w tak znaczącym stopniu, jak sugeruje Kaczor ${ }^{24}$. Na pewno wiele kwestii wymagałoby rozwinięcia. Wydaje się jednak, że założeniem autorki było skłonienie czytelników do spojrzenia, może ponownego, na dotychczasowe osiągnięcia w dyskursie dotyczącym fantasy z innej strony.

22 Zob. S. Lem, Ontologia porównawcza fantastyki, [w:] idem, Fantastyka i futurologia, t. 1, Warszawa 2009, s. 86-91; G. Lasoń, Baśń a fantasy — podobieństwa i różnice, „Fantastyka” 1984, nr 9, s. 51-53; G. Trębicki, Synkretyzm fantasy. Fantasy świata wtórnego: literatura, kultura, mit, Kraków 2014, s. 25-26 n.

${ }^{23}$ K. Kaczor, op. cit., s. 199.

24 Ibidem, s. 217, 251. 


\section{Bibliografia}

\section{Teksty}

Kaczor K., Z „,getta” do mainstreamu. Polskie pole literackie fantasy (1982-2012), Universitas, Kraków 2017.

\section{Opracowania}

Borowski M, Sugiera M., W pułapce przeciwieństw: ideologie tożsamości, Instytut Teatralny Trio, Warszawa 2012.

Bourdieu P., Reguly sztuki. Geneza i struktura pola literackiego, przeł. A. Zawadzki, Universitas, Kraków 2001.

Bourdieu P., Teoria obiektów kulturowych, przeł. A. Zawadzki, [w:] Odkrywanie modernizmu. Przeklady i komentarze, red. R. Nycz, Universitas, Kraków 1998, s. 259-280.

Czapliński P., Powrót centrali, „Kresy” 1995, nr 1-2, s. 31-45.

Gajewska A., Zagłada i gwiazdy. Przeszłość w prozie Stanisława Lema, Wydawnictwo Naukowe UAM, Poznań 2016.

Gajewski K., ,, Reguly sztuki : geneza i struktura pola literackiego”, Pierre Bourdieu, przet. Andrzej Zawadzki, red. nauk. Matgorzata Sugiera, Kraków 2001 [recenzja], „Pamiętnik Literacki” 97, 2006, nr 2, s. 255-266.

Gemra A., Rudolf E., Fantasy, [hasło w:] Słownik literatury popularnej, red. T. Żabski, Wydawnictwo Uniwersytetu Wrocławskiego, Wrocław 2006, s. 149-153.

Gemra A., Fantasy — powrót romansu rycerskiego?, „Literatura i Kultura Popularna” 1998, nr 7, s. $55-73$.

Handke R., Polska proza fantastyczno-naukowa. Problemy poetyki, Ossolineum, Wrocław 1969.

Lasoń G., Baśń a fantasy — podobieństwa i różnice, „Fantastyka” 1984, nr 9, s. 51-53.

Lem S., Ontologia porównawcza fantastyki, [w:] idem, Fantastyka i futurologia, t. 1, Agora, Warszawa 2009, s. 86-91.

Motywy religijne we wspótczesnej fantastyce, red. M.M. Leś, P. Stasiewicz, Wydawnictwo Uniwersytetu w Białymstoku, Białystok 2014.

Ostrowski W., The fantastic and the realistic in literature, „Zagadnienia Rodzajów Literackich” 1966, z. 1, s. 54-71.

Oziewicz M., Magiczny urok Narnii. Poetyka i filozofia „, Opowieści z Narnii” C.S. Lewisa, Universitas, Kraków 2005.

Ponton R., Champ littéraire, [hasło w:] P. Aron, O. Saint-Jacques, A. Viala, Le Dictionnaire de la littérature, Presses Universitaires de France, Paris 2002, s. 84.

Skołuda C., O fantastyce w literaturze, „Ruch Literacki” 1960, nr 3, s. 189-196.

Tkacz M., Baśnie zbyt prawdziwe. Trzydzieści lat fantasy w Polsce, Wydawnictwo Gdański Klub Fantastyki, Gdańsk 2012.

Trębicki G., Fantasy. Ewolucja gatunku, Universitas, Kraków 2007.

Trębicki G., Synkretyzm fantasy. Fantasy świata wtórnego: literatura, kultura, mit, Wydawnictwo LIBRON, Kraków 2014.

Trocha B., Degradacja mitu w literaturze fantasy, Oficyna Wydawnicza Uniwersytetu Zielonogórskiego, Zielona Góra 2009.

Trocha B., Literatura popularna w perspektywie badawczej. Rozważania metodologiczne, [w:] J.Z. Lichański, W. Kajtoch, B. Trocha, Literatura i kultura popularna. Metody: propozycje i dyskusje, Pracownia Literatury i Kultury Popularnej oraz Nowych Mediów, Wrocław 2015, s. 75-105.

Zgorzelski A., Fantastyka, utopia, science fiction. Ze studiów nad rozwojem gatunków, PWN, Warszawa 1980.

Literatura i Kultura Popularna 25, 2019

(C) for this edition by CNS 


\title{
In the power of fantasy - a discourse around the genre of native readers, creators, publishers, critics and researchers
}

\author{
Summary
}

In Poland, the description of 'fantasy' theory arose in the 1960s, including Celestyn Skołuda, Witold Ostrowski, Ryszard Handke, and Andrzej Zgorzelski. Their work was continued by subsequent generations of researchers interested in literature and popular culture, including fantasy.

Fantasy as a type of popular literature has gradually been gaining popularity in Poland. Katarzyna Kaczor, in her monograph Z , getta” do mainstreamu. Polskie pole literackie fantasy (19822012) has analysed phenomena related to the phenomenon of popularity of Polish fantasy literature. Its systematic development covers a wide context of processes related to the formation of the Polish publishing market, its creators, critics, publishers, recipients, as well as the type itself. The author analyses the phenomena occurring in the period 1982-2012. The selected time range includes significant changes that have taken place in the Polish publishing market.

\section{Adam Mazurkiewicz}

ORCID: 0000-0003-3804-6445

University of Łódź, Poland

\section{Literature from the perspective of interpretative anthropology}

https://doi.org/10.19195/0867-7441.25.33

Review: Wojciech Józef Burszta, Mariusz Czubaj, Kryminalna odyseja oraz inne szkice o czytaniu i pisaniu, Wydawnictwo Oficynka, Gdańsk 2017, 303 pp.

Słowa kluczowe: Mariusz Czubaj, Wojciech Józef Burszta, literatura kryminalna, antropologia, gęsty opis, Clifford Geertz

Keywords: Mariusz Czubaj, Wojciech Józef Burszta, crime fiction, anthropology, thick description, Clifford Geertz

"Anthropological framework of (not only) crime fiction" — such a subtitle could be given to the recently-published volume by Wojciech Józef Burszta and Mariusz Czubaj: Kryminalna odyseja oraz inne szkice o czytaniu i pisaniu [Criminal Odyssey and Other Essays on Reading and Writing]. The book consists of articles which the authors have already delivered in the past, which they mention in the attached bibliography (p. 303).

It is not the first book which the authors have written together; let me remind you of Krwawa setka. 100 najwazniejszych powieści kryminalnych [The Bloody 